\title{
EFFECT OF DIFFERENT FILLER LOADING ON FRACTURE RESISTANCE OF CAD/CAM RESIN COMPOSITE RESTORATION IN PREMOLAR TEETH: AN IN VITRO STUDY
}

\author{
Shereen Hafez ${ }^{*}$, Amir Hafez ${ }^{* *}$, Haitham Amr ${ }^{* * *}$ and Hesham A. Aboudorra ${ }^{* * * *}$
}

\begin{abstract}
Objective: to assess the effect of different filler loading on the fracture resistance of CAD/ CAM composite inlays when restoring MOD cavity in premolar teeth.

Materials and methods: A two type of CAD/CAM resin composite block with different amount of filler loading were used in this study as the follow: Grandio Bloc with high filler loading (HFL) about 86\% filler and BRILLIANT Crios with low filler loading (LFL) about 70\% filler. A 40 maxillary premolar were divided equally into four main groups (10 teeth each); a positive control group of unprepared teeth and a negative control group with prepared and unrestored MOD cavity. While the two other restored groups in which teeth with prepared MOD cavities were restored either with the high filler loading Grandio Bloc CAD/CAM resin composite inlay or low filler loading BRILLIANT CAD/CAM resin composite blocks. A standardized MOD cavity were prepared in premolar teeth using the inlay preparation kit. working and master models were fabricated. A new restoration was created in the Cerec in-lab software version. The restoration were processed and cemented in place using Dual-link universal Resin cement. All specimen groups (positive control, negative control and restored groups) were tested for fracture resistance using universal testing machine. Fractured teeth were examined with USB digital microscope at 25X magnification. Twoway ANOVA (Analysis of Variance) was used to compare between groups. Tukey's post-hoc test was used for pair-wise comparison between the mean when ANOVA value were significant. The significance level was set at $\mathrm{P} \leq 0.005$.
\end{abstract}

Results: There was no statistical significant difference between the intact teeth group and HFL GRANDIO inlays and LFL BRIILIANT CRIOS. However there were statistically significant between prepared but not filled teeth groups and all other groups. The HFL GRANDIO inlays restored teeth group recorded high mean value than LFL BRIILIANT CRIOS but without statistically significant difference between them. A mixed type of failure was detected; cohesive failure either within tooth and restoration and adhesive failure along cement line.

\footnotetext{
* Ass. Professor of Conservative Dentistry, Faculty of Dentistry, Cairo University

** Lecturer of Conservative Dentistry, Faculty of Dentistry, Cairo University

*** Lecturer of Fixed Prosthodontic, Faculty of Dentistry, Fayoum University

**** DDS of Fixed Prosthodontic, Faculty of Dentistry, AlAzhar University
} 
Conclusions: the proper balance between filler and polymer matrix was able to improve the mechanical performance of resin composite blocks despite amount of filler loading. The use of $\mathrm{CAD} / \mathrm{CAM}$ resin composite could be considered a perfect choice in the restoration of badly broken vital posterior teeth.

KEY WORDS: Fracture resistance, CAD/CAM composite restoration, Filler loading.

\section{INTRODUCTION}

Due to huge advances in intra-oral imaging and manufacturing technology, there has been a dramatic increase in the use of computer-aided design and manufacturing $(\mathrm{CAD} / \mathrm{CAM})$ materials in dentistry both labside and chairside. The Ceramic and composite block have been introduced to prepare the indirect restorations using $\mathrm{CAD} / \mathrm{CAM}$ systems as promising restorations. ${ }^{[1]}$

Ceramic is a biocompatible and strong material but it is also hard and brittle; these properties affect its clinical performance, durability, and machinability. Regarding ceramics hardness, The ceramic may cause wear of opposing enamel and roughness as it is highly abrasive; also it takes longer time to mill beside ceramic hardness there is its brittleness that may also affect the clinical durability as it lead to chip or crack during processing. Hence it is difficult to manufacture even with $\mathrm{CAD} / \mathrm{CAM}$ systems. ${ }^{[1-3]}$

Although ceramics account for the majority of CAD/CAM materials, there has been considerable progress in the field of resin composite block materials for indirect dental restorations. Over the years, modifications of indirect composite restorations have made such as: alteration of the composition (monomer resins, initiation systems); incorporation of high percentage filler particles; and polymerization modes (using high temperature and pressure for polymerization). ${ }^{[4]}$

CAD/CAM composite has the following main advantages compared to ceramic: it has less hardness and stiffness, and exhibits less wear clinically. It is also less brittle, less catastrophic failure is expected as well as less chipping and crack introduction during manufacturing. Furthermore, they are more easily fabricated, doesn't require post-milling crystallization cycle as ceramic or addition curing cycle, repaired and compatible with milling machine and exhibit better marginal quality. ${ }^{[1,5]}$

CAD/CAM composites can be classified based on their microstructural geometry into two main types, resin with dispersed fillers and polymer infiltrated ceramic networks. The resin infiltrated material represented an intermediate position between ceramics and resin composites, exhibiting wear results corresponding to those of ceramics and resin composites. ${ }^{[1,2]} \mathrm{A}$ few researches has been made on CAD/CAM composite blocks to evaluate their clinical success and performance, therefore this study aimed to assess the effect of different filler loading on the fracture resistance of CAD/ CAM composite inlays when restoring MOD cavity in premolar teeth.

The null hypothesis tested in this study that there will be no significant difference between higher filler loading and low filler loading regarding fracture resistance of resin composite inlays.

\section{MATERIALS AND METHODS}

A two type of CAD/CAM resin composite block with different amount of filler loading were used in this study as the follow: Grandio Bloc with high filler loading (HFL) about 86\% filler and BRILLIANT Crios with low filler loading (LFL) about $70 \%$ filler. The materials used in this study, their composition and manufacture are presented in table 1 . 
Table (1): Product name, composition and manufacture of tested material

\begin{tabular}{|c|c|c|c|}
\hline Product & description & composition & manufacturer \\
\hline $\begin{array}{l}\text { BRILLIANT } \\
\text { Crios } \\
\text { LFL }\end{array}$ & $\begin{array}{l}\text { ReinforcedCAD/CAM } \\
\text { composite bloc for the } \\
\text { fabrication of permanent, } \\
\text { aesthetic single-tooth } \\
\text { restorations. }\end{array}$ & $\begin{array}{l}70 \% \text { of glass and amorphous silica. Cross-linked } \\
\text { methacrylates (Bis-GMA, Bis-EMA, TEGDMA }\end{array}$ & $\begin{array}{l}\text { COLTENE, } \\
\text { Switzerland }\end{array}$ \\
\hline $\begin{array}{l}\text { Grandio Blocs } \\
\text { HFL }\end{array}$ & $\begin{array}{l}\text { Nano-ceramic hybrid CAD } \\
\text { / CAM composite block for } \\
\text { the fabrication of permanent, } \\
\text { aesthetic single-tooth } \\
\text { restorations. }\end{array}$ & $86 \%$ Nanohybrid Filler $14 \%$ UDMA+ DMA & $\begin{array}{l}\text { VOCO GmbH, } \\
\text { Germany, } \\
\text { Cuxhaven }\end{array}$ \\
\hline $\begin{array}{l}\text { Duo-Link } \\
\text { universal }\end{array}$ & $\begin{array}{l}\text { Dual cured resin lutting } \\
\text { cement }\end{array}$ & $\begin{array}{l}\text { Base: } 10-20 \% \text { Ytterbium Fluoride, } 10-30 \% \text { Bisphenol } \\
\text { A Diglycidylmethacrylate,10-30\% Urethane } \\
\text { Dimethacrylate, } 1-5 \% \text { Ytterbium Oxide-Silica, } \\
\text { 1-5\% Tetrahydrofurfuryl Methacrylate, } 1-5 \% \\
\text { Trimethylolpropane Trimethacrylate, }>2 \\
\text { 3-(Trimethoxysilyl)propyl-2-Methyl-2-Propenoic } \\
\text { Acid } \\
\text { Catalyst: } 10-30 \% \text { Bisphenol A } \\
\text { Diglycidylmethacrylate, Dibenzoyl Peroxide, }>1 \\
\text { technically pure }\end{array}$ & $\begin{array}{l}\text { Bisco, Inc. } \\
\text { Schaumburg } \\
\text { USA }\end{array}$ \\
\hline $\begin{array}{l}\text { Futura bond } \\
\text { DC }\end{array}$ & $\begin{array}{l}\text { Dual curing self etching bond } \\
\text { reinforced with nanoparticles }\end{array}$ & $\begin{array}{l}\text { 50-100\%Acidic adhesive monomer, } 5-10 \% \text { BIS } \\
\text { GMA, 5-10\% 2hydroxyethyl methacrylate }\end{array}$ & $\begin{array}{l}\text { Voco GmbH, } \\
\text { Germany, } \\
\text { Cuxhaven }\end{array}$ \\
\hline Bis-Silane & Silane coupling agent & $\begin{array}{l}\text { Part A: } 85 \% \text { ethanol, } 5-10 \% 3 \text { trimethoxysilyl } \\
\text { propyl-2-methyl-2-propenoic acid } \\
\text { Part B: } 30-50 \% \text { ethanol, } 1-5 \% \text { ( } 85 \% \text { phosphoric acid) }\end{array}$ & $\begin{array}{l}\text { Bisco, Inc. } \\
\text { Schaumburg } \\
\text { USA }\end{array}$ \\
\hline
\end{tabular}

\section{Specimen preparation}

A 40 maxillary premolar were divided equally into four main groups (10 teeth each); a positive control group of unprepared teeth and a negative control group with prepared and unrestored MOD cavity. While the two other restored groups in which teeth with prepared MOD cavities were restored either with the high filler loading Grandio Bloc CAD/CAM resin composite inlay or low filler loading BRILLIANT CAD/CAM resin composite blocks.

\section{The selection of teeth:}

Non-carious human maxillary premolar teeth extracted for orthodontics reason, collected from patients at age 20-35 years old, were used in this study. All selected teeth were free of caries, cracks, showed no apparent hypoplastic defect, and having a bucco-lingual dimension at the area of maximum convexity of their crowns to be in the range of 8.4$9.4 \mathrm{~mm}$, as assessed by the use of a digital caliper. The selected teeth were thoroughly cleaned from calculus, tissue deposits, polished with pumice and rotating brush at conventional speed. 


\section{Mounting in acrylic blocks}

Each tooth was individually mounted in polymethyl-methacrylate (PMMA) resin blocks, vertically along their long axis to a depth of $2.0 \mathrm{~mm}$ apically from the cemento-enamel junction (CEJ) from the center of the mesial and distal surfaces. Especially designed cylindrical Teflon molds with internal diameter of $20 \mathrm{~mm}, 30 \mathrm{~mm}$ external diameter and $20 \mathrm{~mm}$ height to accommodate the acrylic resin, were used to fabricate the acrylic blocks. Each mold has a cover fixed to its top by two small pins. In the center of this cover, there is a rounded hole of $5.0 \mathrm{~mm}$ diameter to determine the center of the acrylic block.

The Teflon mold was mounted on the base of the surveyor and a soft mix of polymethyl-methacrylate (PMMA) resin was poured inside the Teflon mold. The center of the acrylic block was determined using the mold cover, then the mold cover was removed while the mix still soft. A paralleling device Surveyor (Ney dental Surveyor, Anaheim CA, USA) was used to mount each tooth inside the acrylic blocks to ensure the centralization and alignment of the specimens to be exactly parallel to the long axis of the tooth. The tooth was then left fixed in its position until the acrylic resin set. The acrylic block with tooth specimen inside it was removed from the mold using finger pressure on its base. The specimens were then stored in distilled water to prevent dehydration of the teeth till the next step.

\section{Cavity preparation}

A standardized MOD cavity were prepared in premolar teeth using the \#4261 inlay preparation kit (Komet Inlay preparation Kit, Brasseler, $\mathrm{GmbH}$, Germany) in a high speed hand piece with water spray, in a following sequence starting with \#845KR, then \#8845KR and ending with \#845KREF. The pulpal floor was at a depth of 3.0 $\mathrm{mm}$ from the occlusal cavo-surface margin of the preparation and an isthmus width of $3.0 \mathrm{~mm}$. The faciolingual dimensions of the proximal boxes were $4.0 \mathrm{~mm}$. Each box had a gingival floor of $1.5 \mathrm{~mm}$ width and an axial wall of $2.0 \mathrm{~mm}$ in height. All preparations were free of undercuts with buccal and lingual walls having a $6-10^{\circ}$ divergence toward the occlusal surface. The external angle at the gingival floor was $90^{\circ}$ to the external surface located $0.5 \mathrm{~mm}$ coronal to CEJ. During cavity preparation, the cavity dimensions were checked with a digital caliber.

\section{Fabrication of working and master models:}

A master model was fabricated on the basis of the impression in the usual manner. Impressions for acrylic blocks and specimens inside them were taken using condensation silicon impression material in a plastic cup (Speedex, Coltène/ Whaldent, Switzerland). Dies were fabricated using extra hard stone. A double pour was made in dental stone to produce working and master models.

\section{Inlay construction For MOD cavities:}

\section{Step 1: Scanning of the die}

A new restoration was created in the Cerec inlab software version 3.60 (Sirona Dental Systems GmbH, D-64625 Bensheim, Germany), restoration data were entered in the window of the in-lab user interface. The die was then prepared by spraying it with a light reflecting anti-glare spray "Cerec optispray", and then was fixed using plasticine on the shifting plate of the in-lab extra oral scanner "inEos". The shifting plate with the prepared tooth fixed on it was then positioned on the XY table of the inEos for taking the optical impression. A top view scan was done of the preparation surface, the in-lab software then uses that image for transforming it into a 3-D virtual model.

\section{Step 2: Designing the restorations on the software.}

The 3-D virtual model displayed on the design window was then used to design the restoration with 
the help of the software given tools in the view and design window boxes. The preparation was digitally trimmed to hide unnecessary areas on the 3-D virtual model, with the aid of the line tool by drawing a line that represents the border to the data to be trimmed. The preparation margins was then drawn on the 3-D virtual model of the preparation as a blue closed line. The insertion axis of the restoration to be made was then adjusted to be oriented vertically to the occlusal surface of the model. After that the Lee culp anatomy database was selected for the shape of the restorations. The setting for the machining of restorations for occlusal and lateral wall-thickness was entered with a $70 \mu \mathrm{m}$ cement space, and then the virtual restorations were built according to the lee culp anatomy selected shape by using the software tools in the design windows box and the cut tool, which can take a segmental cut through any plane of the 3-D model.

\section{Step 3: Milling process.}

After the restoration had been designed, the milling preview window was activated to start the milling process, then the type and size of the blocks were selected. The in-lab MC XLmilling machine was then activated and the composite CAD block was manually fixed in the spindle of the milling machine, then door was closed and the milling process was performed. For the purpose of standardization, the milling process was repeated for all the blocks of the same materials with the exact same milling preview design saved in the software to produce identical restorations. The processed restoration was then checked for any defects such as cracks or fissures or material chipping and the defected restoration was rejected. Plolishing of the restoration was then done with standards composite polishers (medium, fine and extra fine diamonds).

\section{Inlays cementation procedures:}

The surface of the prepared sections were treated with The CoJet ${ }^{\circledR}$ system using $30 \mu \mathrm{m}$ silica coated alumina powder. the surface of all groups were then silanized according to manufacturer instructions using Bis-Silane (Bisco) for 60 seconds and air dried for 5 seconds then bonding agent Futura bond DC was applied according to the manufacturer instruction using microbrush on the restoration fitting surface and the cavity walls and margin then light cured for 10 seconds using LED curing unit (Dr's light AT, Good doctors co.ltd. korea) with light intensities $(1400 \mathrm{~mW} / \mathrm{cm} 2)$. Dual-link universal Resin cement (Bisco) was then used for cementation of the restoration and light cured for 40 sec from all aspects after removal of excess cement.

\section{Fracture resistance test:}

All specimen groups (positive control, negative control and restored groups) were tested for fracture resistance using universal testing machine (Model LRX-plus; Lloyd instruments Ltd., Fareham, UK). The specimens were then loaded in compression until failure by fracture of either restoration or tooth or both. Compressive load was applied at cross head speed of $0.5 \mathrm{~mm} / \mathrm{min}$ by means of steel cylinder with rounded end of $5.7 \mathrm{~mm}$ diameter, adjusted parallel to long axis of tooth. The rounded end was contacting the occlusal inclined planes of both buccal and lingual cusps. Loads were recorded in Newton of force using PC software (Nexygen-4.1;Lloyd instruments). Fractured teeth were examined with USB digital microscope at $25 \mathrm{X}$ magnification and photographed using image analysis software (ViewTi Capture 1.3.0.1).

\section{Statistical analysis}

Numerical data for fracture resistance were presented as mean and standard deviation value. Two-way ANOVA (Analysis of Variance) was used to compare between groups. Tukey's post-hoc test was used for pair-wise comparison between the mean when ANOVA value were significant. The significance level was set at $\mathrm{P} \leq 0.005$. Statistical analysis was performed with SPSS 18.0 (Statistical 
Package for Scientific Studies, SPSS, Inc., Chicago, IL, USA) for Windows.

\section{Results of Fracture resistance}

Table (2) and figure (1) represent the fracture resistance results in mean and standard deviation values $($ Mean \pm SD) recorded in Newton $(N)$ of the different tested groups. The results revealed that the intact teeth group recorded the highest fracture resistance mean value of $1213 \pm 15.45$ followed by HFL GRANDIO inlays $1208 \pm 12.05$, then those LFL BRIILIANT CRIOS $1205 \pm$ 17.49. Meanwhile, the prepared but not filled teeth group recorded the lowest fracture resistance mean value $770 \pm 8.28$.

There was no statistical significant difference between the intact teeth group and HFL GRANDIO inlays and LFL BRIILIANT CRIOS. However there were statistically significant between prepared but not filled teeth groups and all other groups. On the other hand, The HFL GRANDIO inlays restored teeth group recorded high mean value than LFL BRIILIANT CRIOS but without statistically significant difference between them.

Table (2): The fracture resistance results $(\mathrm{Mean} \pm \mathrm{SD})$ of different tested groups

\begin{tabular}{|c|c|c|c|}
\hline Group & Mean \pm SD & Ranking & P value \\
\hline Intact tooth & $1213 \pm 15.45$ & A & \\
\cline { 1 - 3 } Prepared tooth & $770 \pm 8.28$ & C & \multirow{2}{*}{$0.0001 *$} \\
\hline $\begin{array}{c}\text { HFL } \\
\text { Grandio blocs }\end{array}$ & $1208 \pm 12.05$ & A & \\
\hline $\begin{array}{c}\text { LFL } \\
\text { Brilliantcrios }\end{array}$ & $1205 \pm 17.49$ & A & \\
\hline
\end{tabular}

*; significant $(p<0.05) \quad$ calc.; calculated tab.; tabulated

Different letter indicating statistical significance between $\operatorname{groups}(p<0.05)$

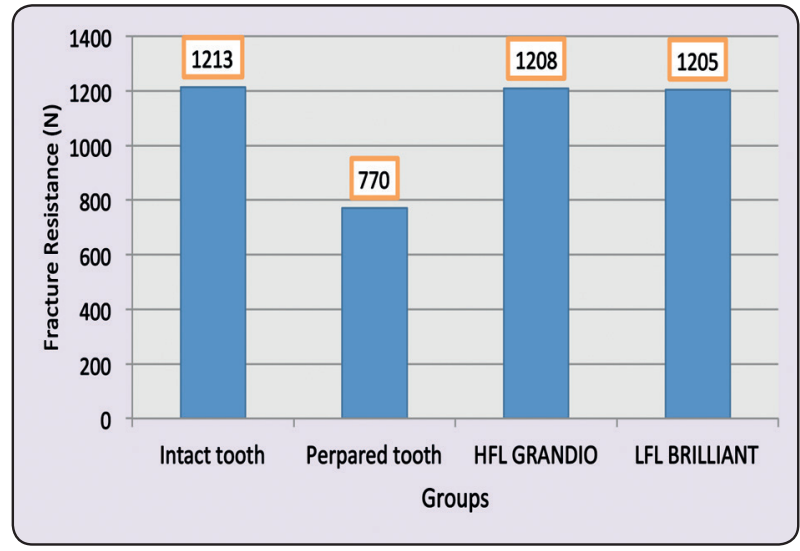

Fig. (1): A column chart of fracture resistance mean values for all groups

\section{Failure mode analysis}

Fractured teeth were examined with USB digital microscope at $25 \mathrm{X}$ magnification and photographed using image analysis software (ViewTi Capture 1.3.0.1). A mixed type of failure was detected; cohesive failure either within tooth and restoration and adhesive failure along cement line. Figure 2

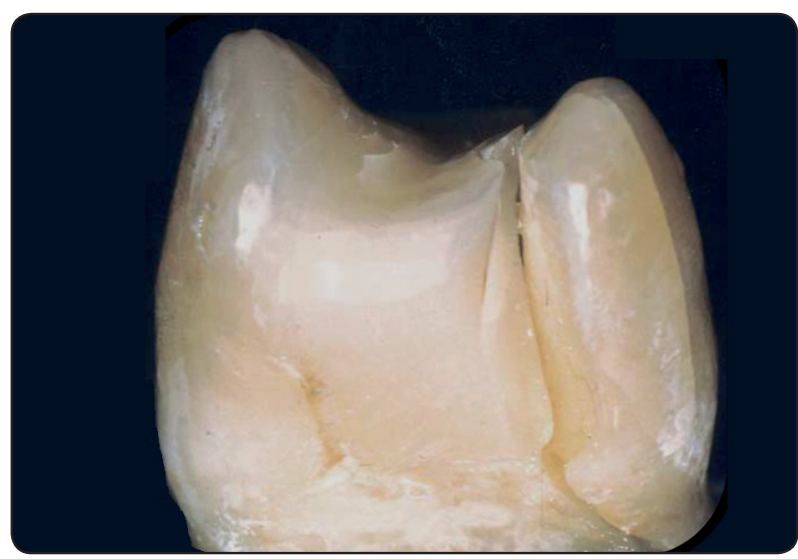

Fig. (2): mixed failure mode was detected

\section{DISCUSSION}

It was noticed that $\mathrm{CAD} / \mathrm{CAM}$ composite blocks had different microstructure as well as variable filler weight percentages and hence differences in the tested mechanical properties. However, it seems that the filler percentages have a more considerable role in these properties than do the microstructural constituents. ${ }^{[1]}$ Thus in the current study two CAD/ 
CAM resin composite inlays with different filler loading are used to restore MOD cavity in premolar teeth and then subjected to fracture resistance test to determine their mechanical performance under load.

In this study two type of Ceramic reinforced CAD/CAM hybrid resin composite blocks where used either Grandio Bloc or Brilliant Crios. The aim of any dental restorative material is to have similar characteristics to that of the tooth structure particularly one there is extensive loss in tooth structure involving one or both marginal ridges as in case of Inlays, overlays in vital teeth or endocrown in endodontically treated teeth. Hence, resin ceramic combination in a network structure exhibits the positive characteristics of ceramics and resin. This material has low rigidity, hardness, and stiffness but high flexibility and fracture toughness. Resin with dispersed ceramic fillers has good fracture and wear resistance and high compressive strength. $\mathrm{CAD} / \mathrm{CAM}$ composite materials have comparable hardness and elastic moduli to tooth structure. Also it combine ceramic good strength with composite lower hardness. ${ }^{[1]}$

The experimental use of natural teeth presents problems due to anatomic variations and the heterogeneous nature of tooth matter. The selection of intact natural maxillary premolar seemed to represent the acceptable possible option to simulate clinical situations. The bucco-lingual dimensions of the selected teeth at the area of maximum convexity of their crowns was in the range of 8.4-9.4 $\mathrm{mm}$ in order to standardize the premolar size to obtain reliable data. ${ }^{[6]}$ A paralleling device (surveyor) was used to mount each tooth inside the acrylic block to be exactly parallel to its long axis to assure that the mechanical load will be applied on the desired angulation to provide the most accurate results.

For MOD cavity design, an inlay preparation kit was used in order to obtain standardized MOD cavities in premolar teeth. All of the burs are diamonds, have rounded tips that develop a smooth transition between the floor and wall surfaces of the preparation; eliminating the sharp edges so decreases the chances of post-operative tooth fracture. The burs' built-in taper of $6^{\circ}$ to $10^{\circ}$ delivers an ideal insertion path for the restoration once it is completed. All of the burs in the kit have different width, allowing the practitioner to select the minimal dimension of buccolingual preparation required for a successful restoration. Furthermore, the burs create $\mathrm{a} 90^{\circ}$ angle at the cavo-surface margin for easier cementation and an enhanced functional distribution of forces on the occlusal surface. ${ }^{[7]}$

The fracture resistance test in this study was performed by universal testing machine at cross head speed of $0.5 \mathrm{~mm} / \mathrm{min}$ according to the ISO standard recommendation for the rate of loading as this cross head speed is more sensitive in measuring the fracture resistance of restored teeth. The compressive load was applied by mean of steel cylinder with rounded end of $5.7 \mathrm{~mm}$ diameter adjusted parallel to long axis of tooth. The rounded end was contacting the occlusal inclined planes of both buccal and lingual cusps beyond the margins restorations. ${ }^{[5,6]}$

The result of the present study show that both tested material able to restore the tooth fracture resistance close to the control non restored tooth and this was in agreement with Reymus et al ${ }^{[8]}$. Resin composite has a lower elastic modulus so more load is absorbed within the composite restorations and it transmits less of the applied load to the underlying tooth structure. More flexible and less rigid materials may be desirable for the restoration of posterior teeth given the inherent ability of teeth to flex under occlusal loading.

In other word Rosentritt et al ${ }^{[9]}$ stated that there was a trend to a correlation between in vitro performance and fracture results and the individual material properties: as expected materials with lower modulus of elasticity and flexural strength provided 
lower fracture resistance. Previous studies have shown that resin-based materials and composites have higher shock absorbing capacity than ceramics

However this result was contradicted by $S t$ george et $a l^{[6]}$ although bonded inlay restorations replace the lost tooth structure and recreate the anatomic form of a prepared tooth, they do not reestablish the fracture resistance of the tooth to its original level as MOD inlays created higher stress levels at the internal surfaces of the cavity.

The null hypothesis of this study can be confirmed as the result show a non significant difference in fracture resistance of Grandio Bloc with its high filler loading and BRILLIANT Crios with its low filler loading. The comparable result record by brilliant although its low filler loading was explained by Matzinger et al $2019^{[2]}$, who stated that can probably be attributed to a balanced mixture of small $(\approx 20 \mathrm{~nm})$ and medium fillers $(\approx 1 \mu \mathrm{m})$ in the resin composite which improve both physical and mechanical properties of this material.

It has been reported that material properties and strength such as Fracture toughness is influenced by the depth of a crack. A superficial cracks result from wear and surface roughness, can lead to cracking or further crack propagation. Resin composites with smaller filler can be compacted more strongly, and consequently less polymer matrix is exposed to the direct environmental force. Bigger fillers might be exposed more easily and can also be lost, resulting in exposure of the matrix and ultimately a reduction in wear resistance and crack propagation. ${ }^{[2,10]}$

Despite the differences in composition of both tested material of this study as the Grandio bloc consist of $86 \%$ Nanohybrid ceramic Filler with 14\% UDMA+ DMA and Brilliant Crios consist of $70 \%$ of glass and amorphous silica in Cross-linked methacrylates Bis-GMA, Bis-EMA and TEGDMA matrix; however there was no significant difference in their mechanical performance under fracture load. This was in disagreement with Tsujimoto et al ${ }^{[10]}$ who stated that the type of resin matrix, degree of conversion, and surface treatment of the filler affect to the mechanical properties of CAD/CAM resin composites in the same manner as has been reported from previous study of resin composites revealed correlations between filler size, distribution of filler particles, and flexural properties.

Furthermore Nguyen et al ${ }^{[11]}$ held study to compare the mechanical properties of $\mathrm{CAD} / \mathrm{CAM}$ resin composite blocks using BIS-GMA polymer matrix and experimental resin composite blocks based on UDMA matrix and found that showed that the mechanical properties of UDMA block obtained were superior to those of a commercial BIS-GMA block due to the presence of a sintered network that significantly increased strength and hardness, and UDMA matrix allow more rigid and denser network with higher flexural.

The explanation for the mixed type of fracture mode in the current study is that the adhesively bonded inlay using low modulus restorative materials may not only restores the missing tissues, but also reinforces the remaining structure of the prepared tooth, as it limits the stress intensity transmitted to the remaining tooth structures. Thus, composite resin inlays used in the present study may redistribute stresses and may present elastic biomechanics similar to those of the sound tooth. ${ }^{[12]}$

\section{CONCLUSION}

Under limitation of current study the following conclusion can be driven: the proper balance between filler and polymer matrix was able to improve the mechanical performance of resin composite blocks despite amount of filler loading. The use of CAD/CAM resin composite could be considered a perfect choice in the restoration of badly broken vital posterior teeth. 


\section{REFERENCES}

1. Alamoush, R., et al., Effect of the Composition of CAD/ CAM Composite Blocks on Mechanical Properties. 2018. $1-8$.

2. Matzinger, M., et al., Polishing effects and wear performance of chairside CAD/CAM materials. Clinical Oral Investigations, 2019. 23(2): p. 725-737.

3. Strasser, T., et al., Roughness, surface energy, and superficial damages of CAD/CAM materials after surface treatment. Clinical Oral Investigations, 2018. 22(8): p. 2787-2797.

4. Nguyen, J.-F.o., et al., Resin composite blocks via high-pressure high-temperature polymerization. Dental Materials, 2012. 28(5): p. 529-534.

5. Okada, R., et al., Fracture strength testing of crowns made of CAD/CAM composite resins. Journal of Prosthodontic Research, 2018. 62(3): p. 287-292.

6. St-Georges, A.J., et al., Fracture resistance of prepared teeth restored with bonded inlay restorations. The Journal of prosthetic dentistry, 2003. 89(6): p. 551-557.

7. de Andrade, O.S., F. Mario, and M.A.J.R. Montes, Marginal adaptation and microtensile bond strength of composite indirect restorations bonded to dentin treated with adhesive and low-viscosity composite. Dental Materials, 2007. 23(3): p. 279-287.

8. Reymus, M., et al., Bonding to new CAD/CAM resin composites: influence of air abrasion and conditioning agents as pretreatment strategy. Clinical Oral Investigations, 2019. 23(2): p. 529-538.

9. Rosentritt, M., et al., In vitro performance and fracture resistance of $\mathrm{CAD} / \mathrm{CAM}$-fabricated implant supported molar crowns. Clinical Oral Investigations, 2017. 21(4): p. 1213-1219.

10. Tsujimoto, A., et al., Influence of thermal cycling on flexural properties and simulated wear of computer-aided design/computer-aided manufacturing resin composites. Operative dentistry, 2017.42(1): p. 101-110.

11. Nguyen, J.F., et al., High-temperature-pressure polymerized resin-infiltrated ceramic networks. Journal of dental research, 2014. 93(1): p. 62-67.

12. Dejak, B. and A. Mlotkowski, Three-dimensional finite element analysis of strength and adhesion of composite resin versus ceramic inlays in molars. The Journal of prosthetic dentistry, 2008. 99(2): p. 131-140. 